\title{
Ensuring equitable access to sick leave
}

\author{
Jody Heymann MD PhD, Mark Daku MA
}

$\mathrm{D}$ espite medicine's impressive advances, there are still simple solutions to reduce the likelihood of illness and to speed up recovery that are underused. Paid sick leave with job protection is one such example in Canada. At the federal level, the Employment Insurance system provides income support to employees who require long-term absences from work because of illness. However, the Canadian system has two major gaps: both paid short-term leave for everyday illnesses and job protection during sick leave of any duration depend on provinces and some guarantee none.

Paid sick leave gives workers the opportunity to seek medical care and speeds recovery. Beyond individual needs, it is in everyone's interest to ensure that employees who are sick can stay at home: people with contagious diseases who go to work put their coworkers and clients at risk of infection, which can lead to increased general morbidity and productivity losses. ${ }^{1,2}$ The Public Health Agency of Canada, the World Health Organization and every major public health body recommend that people stay home from work when they have influenza. Leading medical and public health associations also recommend that people who handle food not go to work when they have gastroenteritis or other contagious diseases.

However, many employees cannot follow these recommendations if it means forgoing their wages or risking their jobs. Without paid sick days, restaurant workers, for example, may go to work sick even with an illness that can be spread through food handling..$^{3-5}$ The same is true for individuals caring for older adults at home or in long-term care facilities. Older adults are particularly vulnerable to serious consequences from infectious diseases. Employees who have access to paid sick leave are more likely to stay home when advised to do so by a physician; employees with no sick leave are more likely to go to work and expose others to infection. ${ }^{6}$

The importance of providing paid sick leave is well-recognized around the world. Some form of paid social safety net for employees who are sick is guaranteed in 170 countries; Canada is one of them. For long-term illnesses, Canada's federal Employment Insurance system provides eligible employees with benefits paid at $55 \%$ of average earnings for up to 15 weeks per year. Up to six weeks of this leave in each six-month period can be used to care for a family member with a life-threatening illness. To be eligible, claimants must be employed, have accumulated 600 hours of insurable employment during the previous year (or from the start of a previous claim), and have had their weekly earnings reduced by more than $40 \%$.

This policy provides important income support for many Canadians. However, these benefits are activated only after an employee has been too sick to work for two weeks, which is too long to apply to most everyday illnesses. Until federal benefits begin, employees must rely on provincial sick leave mandates, most of which do not guarantee any pay during the first two weeks of illness. Only Prince Edward Island mandates short-term paid sick leave, and this applies only for one day and only for employees who have been employed by the same company for at least five consecutive years.

Moreover, although the federal system provides income support during longer sick leaves, job protection during this leave depends on provincial and territorial policy. Alberta, British Columbia and Nunavut do not offer guaranteed job protection in the case of illness. Manitoba, Nova Scotia and Prince Edward Island guarantee only three days per year of job protection during illness; New Brunswick and the Northwest Territories guarantee five days; and the province of Newfoundland and Labrador guarantees seven days. Ontario guarantees 10 days of job protection, but only to employees in a business with 50 or more employees. Only two provinces guarantee job protection for

\section{KEY POINTS}

- Working while sick can slow recovery and put coworkers and others at risk.

- Paid sick leave is guaranteed by 170 countries: the leave begins immediately in 129 of these countries and is guaranteed for six or more months in 100 countries.

- Canada provides federally guaranteed income support to employees with a serious illness, but only after two weeks of illness, and to employees caring for a family member with a life-threatening illness.

- Most provinces and territories guarantee only one week or less of job protection during illness, which is far below the norm globally. 
employees in the case of injury or illness requiring longer absences. Saskatchewan provides up to 12 days per year for a nonserious injury or illness and up to 12 weeks per year for a more serious medical problem; Quebec mandates up to six months of job-protected leave.

What would it take for Canada to fully protect the health of employees and their families? In some areas, Canada's sick leave policy is strong. Federal benefits provide most Canadians with income support that is comparable to sick leave benefits in many countries for periods of personal illness, although it is noteworthy that 100 countries provide paid sick leave for six or more months. In the case of guaranteeing income while employees need to care for a family member with a life-threatening illness, Canada is ahead of much of the world.

However, at the provincial and territorial levels, which govern labour law and employer behaviour, much more must be done to protect employees. The single most important step would be to guarantee that people do not lose their jobs when they get sick. More than half of the provinces and territories require that employers hold jobs for sick employees for one week or less, and three provinces do not require any job protection. These weak provisions place Canada behind other advanced economies and many low- and middle-income countries. This is in sharp contrast to the job protection of eight weeks or more that is provided for compassionate leave in much of Canada for serious family illnesses.

Policy-makers and practitioners should work together to ensure that each province passes at least basic legislation requiring all employers to hold a job for a sick employee for 10 days. This policy would cost employers little as employers would likely not be able to hire a replacement in such a short time period. Ensuring job protection will not impede Canada's competitiveness; ${ }^{7,8}$ if anything, it will enhance it. Ensuring paid shortterm leave is affordable and increases the likelihood that workers with contagious diseases will stay at home.

The more difficult question is what to do in the case of a lengthy illness. Canada has already taken the crucial step of guaranteeing income support during long-term sick leave to employees such as those receiving treatment for cancer, heart disease, and other serious chronic and long-term acute illnesses. Together, the provincial, territorial and federal governments need to address what happens when individuals who have been sick for a long time are ready to return to work. Labour laws in Quebec and Saskatchewan have addressed this by mandating that employers hold jobs for long periods. The feasibility of job protection of two months for infrequent serious events is demonstrated by the number of provinces that provide this for life-threatening family illnesses. Although job protection may be more feasible for larger employers or for positions where temporary workers can easily be hired, some means of ensuring that serious illness does not land people in longterm poverty because of unemployment should be addressable by all provinces and territories. Where provinces and territories are not going to protect the jobs of individuals out of work due to an injury or illness requiring longer recovery, they should have support and assistance in place to facilitate the transition to new jobs.

Regardless of where they live, Canadians should not have to choose between keeping a job and caring for their health and the health of their communities.

\section{References}

1. Hemp P. Presenteeism: at work - but out of it. Harv Bus Rev 2004;82:49-58. Available: http://hbr.org/2004/10/presenteeismat-work-but-out-of-it/ar/1 (accessed 2013 Dec. 15).

2. Lovell V. No time to be sick: Why everyone suffers when workers don't have paid sick leave. Washington (DC): Institute for Women's Policy Research; 2003. Available: www.aecf.org/KnowledgeCenter /Publications.aspx?pubguid=\%7B50A11398-25A7-41D0-8B56 -2C2276D9BC9B\%7D (accessed 2013 Dec. 15).

3. Williams C, Drago R, Miller K. 44 million US workers lacked paid sick days in 2010: 77 percent of food service workers lacked access. Washington (DC): Institute for Women's Policy Research; 2011. Available: www.iwpr.org/publications/pubs/44-million-u.s.-workers -lacked-paid-sick-days-in-2010-77-percent-of-food-service-workers -lacked-access (accessed 2013 Dec. 15).

4. Gould LH, Rosenblum I, Nicholas D, et al. Contributing factors in restaurant-associated foodborne disease outbreaks, FoodNet Sites, 2006 and 2007. J Food Prot 2013;76:1824-8.

5. Aronsson G, Gustafsson K, Dallner M. Sick but yet at work: an empirical study of sickness presenteeism. J Epidemiol Community Health 2000;54:502-9.

6. Johns G. Presenteeism in the workplace: a review and research agenda. J Organ Behav 2010;31:519-42.

7. Heymann SJ, Earle A. Raising the global floor: dismantling the myth that we can't afford good working conditions for everyone. Redwood City (CA): Stanford University Press; 2010.

8. Earle A, Heymann SJ. A comparative analysis of paid leave for the health needs of workers and their families around the world. J Comp Policy Anal 2006;8:241-57.

Affiliations: Department of Epidemiology (Heymann), Fielding School of Public Health, University of California, Los Angeles, Los Angeles, Calif.; Department of Political Science (Daku), McGill University, Montréal, Que.

Contributors: Jody Heymann drafted and developed the article. Jody Heymann supervised the collection of global and Canada-wide data on sick leave policy. Mark Daku updated all provincial and territorial sick leave policies. Both authors contributed substantially to the writing and revising of the article and approved the final version submitted for publication. 